\title{
DÜBLIN
}

Technological University Dublin

ARROW@TU Dublin

Articles

Crest: Centre for Research in Engineering

Surface Technology

2010-05-01

\section{Highly Visible Light Active TiO2-xNx Heterojunction Photocatalysts}

\author{
Vinodkumar Etacheri \\ Technological University Dublin \\ Michael Seery \\ Technological University Dublin, michael.seery@tudublin.ie \\ Steven Hinder \\ University of Surrey
}

See next page for additional authors

Follow this and additional works at: https://arrow.tudublin.ie/cenresart

Part of the Chemistry Commons

\section{Recommended Citation \\ Etacheri, V., Seery, M., Hinder, S., Pillai, S. (2010) : Highly Visible Light Active TiO2-xNx Heterojunction Photocatalysts. Chemistry of Materials, Vol. 22, 2010, pp.3843-3853. doi:10.1021/cm903260f}

This Article is brought to you for free and open access by the Crest: Centre for Research in Engineering Surface Technology at ARROW@TU Dublin. It has been accepted for inclusion in Articles by an authorized administrator of ARROW@TU Dublin. For more information, please contact arrow.admin@tudublin.ie, aisling.coyne@tudublin.ie,gerard.connolly@tudublin.ie.

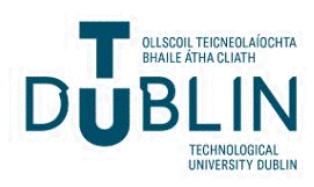


Authors

Vinodkumar Etacheri, Michael Seery, Steven Hinder, and Suresh Pillai

This article is available at ARROW@TU Dublin: https://arrow.tudublin.ie/cenresart/12 
Antenna \& High Frequency Research Centre

\section{Articles}

Dublin Institute of Technology

Year 2010

\section{Highly Visible Light Active TiO2-xNx Heterojunction Photocatalysts}

Suresh C. Pillai

DIT, suresh.pillai@dit.ie
Michael K. Seery

DIT, michael.seery@dit.ie

This paper is posted at ARROW@DIT.

http://arrow.dit.ie/ahfrcart/1 


\section{— Use Licence}

\section{Attribution-NonCommercial-ShareAlike 1.0}

You are free:

- to copy, distribute, display, and perform the work

- to make derivative works

Under the following conditions:

- Attribution.

You must give the original author credit.

- Non-Commercial.

You may not use this work for commercial purposes.

- Share Alike.

If you alter, transform, or build upon this work, you may distribute the resulting work only under a license identical to this one.

For any reuse or distribution, you must make clear to others the license terms of this work. Any of these conditions can be waived if you get permission from the author.

Your fair use and other rights are in no way affected by the above.

This work is licensed under the Creative Commons Attribution-NonCommercialShareAlike License. To view a copy of this license, visit:

- URL (human-readable summary):

http://creativecommons.org/licenses/by-nc-sa/1.0/

- URL (legal code):

http://creativecommons.org/worldwide/uk/translated-license 
Chemistry of Materials | 3b2 | ver.9 | 27/5/010 | 12:38 | Msc: cm-2009-03260f | TEID: lrk00 | BATID: 00000 | Pages: 10.96

\title{
Highly Visible Light Active $\mathrm{TiO}_{2-x} \mathrm{~N}_{x}$ Heterojunction Photocatalysts ${ }^{\dagger}$
}

\author{
Vinodkumar Etacheri, ${ }^{\star \S}$ Michael K. Seery, ${ }^{\S}$ Steven J. Hinder," and Suresh C. Pillai*** \\ * Centre for Research in Engineering Surface Technology (CREST), FOCAS Institute, and \\ ${ }^{\S}$ School of Chemical and Pharmaceutical Sciences, Dublin Institute of Technology, Kevin Street, Dublin 8 , \\ Ireland, and "The Surface Analysis Laboratory, Faculty of Engineering and Physical Sciences, \\ University of Surrey, Guildford, Surrey, GU2 7XH, United Kingdom
}

Received October 23, 2009. Revised Manuscript Received May 10, 2010

\begin{abstract}
Nitrogen doped anatase-rutile heterojunctions are successfully synthesized through an ethylenediaminetetraacetic acid (EDTA) modified sol-gel process. An FT-IR study of EDTA modified $\mathrm{TiO}_{2}$ gel confirms the existence of an ionic intermediate (as indicated by a $\Delta v$ value of $233 \mathrm{~cm}^{-1}$ ). Differential scanning calorimetry (DSC), X-ray diffraction (XRD), and Raman spectroscopy are employed to study the phase evolution, phase purity, and crystallite size of samples. Formations of $\mathrm{O}-\mathrm{Ti}-\mathrm{N}$ and $\mathrm{N}-\mathrm{Ti}-\mathrm{N}$ bonds in calcined samples are confirmed using XPS and FT-IR spectroscopy. All EDTA modified samples show significantly higher visible light photocatalytic activity than the unmodified sample. The most active nitrogen doped heterojunction obtained at $400{ }^{\circ} \mathrm{C}$ exhibits 9-fold visible light activity in comparison to the standard photocatalyst Degussa P-25. It is proposed that the photo excited electrons (from the visible midgap level) are effectively transferred from the conduction band of anatase to that of rutile causing effective electron-hole separation, which is responsible for the higher visible light activity and lower photoluminescence (PL) intensity.
\end{abstract}

\section{Introduction}

Unique properties of nanosized catalysts such as quantum confinement and high surface to volume ratio make them highly efficient. Among various catalysts, titania nanomaterials find wide applications in the field of solar cells, ${ }^{1}$ organic synthesis, ${ }^{2}$ water and air purification, ${ }^{3}$ cancer therapy, ${ }^{4}$ cathodic corrosion protection, and self-cleaning antibacterial materials. ${ }^{5,6}$ High redox potential, chemical stability, inexpensiveness, and non toxicity of titania made it superior to other semiconductor photocatalysts in its class. Among the three polymorphs, it is generally agreed that the anatase phase has the highest photoactivity followed by rutile and brookite. The efficiency of titania photocatalysts strongly depends on several factors, including phase purity, surface area, crystallite size, amount and nature of dopants, method of preparation, and anataserutile ratio. ${ }^{7-9}$

\footnotetext{
${ }^{\dagger}$ This paper is dedicated to Professor John M. Kelly, C. Chem. FRSC on the occasion of completing his 37 years of teaching and research (celebration of chemistry) at the Trinity College Dublin, Ireland.

*To whom correspondence should be addressed. E-mail: suresh.pillai@ dit.ie.

(1) O’Regan, B.; Grätzel, M. Nature 1991, 353, 737

(2) Kraeutler, B.; Bard, A. J. J. Am. Chem. Soc. 1978, 100, 2239.

(3) Ollis, D. F.; Al-Ekabi, H. Photocatalytic Purification and Treatment of Water and Air; Elsevier: Amsterdam, The Netherlands, 1993.

(4) Cai, R.; Kubota, Y.; Shuin, T.; Sakai, H.; Hashimoto, K.; Fujishima, A. Cancer Res. 1992, 52, 2346.

(5) Yuan, J.; Tsujikawa, S. J. Electrochem. Soc. 1995, 142, 3444

(6) Honda, H.; Ishizaki, A.; Soma, R.; Hashimoto, K.; Fujishima, A. J. Illum. Eng. Soc. 1998, 42.

(7) Kavan, L.; Grätzel, M.; Gilbert, S. E.; Klemenz, C.; Scheel, H. J. J. Am. Chem. Soc. 1996, 118, 6716-6723.

(8) Toyoda, M.; Nanbu, Y.; Nakazawa, Y.; Hirano, M.; Inagaki, M. Appl. Catal., B 2004, 49, 227.

(9) Beyers, E.; Cool, P.; Vansant, E. F. J. Phys. Chem. B 2005, 109, 10081.
}

The wide band gap $(3.2 \mathrm{eV})$ of the anatase titania confines its application to UV light $(\lambda \leq 387.5 \mathrm{~nm})$ activation. Even though the high temperature stable rutile phase can absorb visible light (up to $\sim 412 \mathrm{~nm}$ ), its activity is limited as a result of low surface area, low redox potential, and faster electron hole recombination rate. ${ }^{10}$ The development of a highly visible light active catalyst is necessary to effectively exploit sunlight or light from artificial sources. Various methods such as metal or non-metal doping, using reduced forms of $\mathrm{TiO}_{\mathrm{X}}(\mathrm{X}<2)$ photocatalyst, dye sensitization, and optimization of phase composition has been investigated by previous researchers. ${ }^{11-13}$

Titania doped with main group elements has attracted great interest after the report of nitrogen and other anion (S, C, and F) doped visible-light active (VLA) titania catalyst by Asahi and co-workers. ${ }^{14}$ These second-generation $\mathrm{TiO}_{2}$ materials were photoactive over the UV and visiblelight region. Controversy still remains about the nature of the dopant species and electronic structure of nitrogen doped titania, which is highly dependent on the method of preparation. Some researchers proposed the existence of surface adsorbed $\mathrm{NO}_{\mathrm{X}}$ and $\mathrm{NH}_{\mathrm{X}}$, while others proposed the presence of lattice nitrogen. Recently, Valentine et al. demonstrated the electronic structure of nitrogen doped

(10) Miyagi, T.; Kamei, M.; Mitsuhashi, T.; Ishigaki, T.; Yamazaki, A. Chem. Phys. Lett. 2004, 390, 399-402.

(11) Kang, M. G.; Park, N. G.; Park, Y. J.; Ryu, K. S.; Chang, S. H. Sol. Energy Mater. Sol. Cells 2003, 75, 475.

(12) Siemon, U.; Bahnemann, D.; Testa, J. J.; Rodŕguez, D.; Litter, M. I.; Bruno, N. J. Photochem. Photobiol., A 2002, 148, 247.

(13) Nakamura, I.; Negishi, N.; Kutsuna, S.; Ihara, T.; Sugihara, S.; Takeuchi, K. J. Mol. Catal. A: qChem. 2000, 161, 205

(14) Asahi, R.; Morikawa, T.; Ohwaki, T.; Aoki, K.; Taga, Y. Science 2001, 293, 269-275. 
(15) Valentin, C. D.; Pacchioni, G.; Selloni, A.; Livraghi, S.; Giamello, E. J. Phys. Chem. B 2005, 109, 11414-11419.

(16) Torres, G. R.; Lindgren, T.; Lu, J.; Granqvist, C.-G.; Lindquist, S.-E. J. Phys. Chem. B 2004, 108, 5995-6003.

(17) Junin, C.; Thanachayanont, C.; Euvananont, C.; Inpor, K.; Limthongkul, P. Eur. J. Inorg. Chem. 2008, 974-979.

(18) Kawahara, T.; Konishi, Y.; Tada, H.; Tohge, N.; Nishii, J.; Ito, S. Angew. Chem., Int. Ed. 2002, 41(15), 2811-2813.

(19) Balasubramanian, G.; Dionysiou, D. D.; Suidan, M. T.; Baudin, I.; Laine, J. M. Appl. Catal., B 2004, 47, 73-84.

(20) Pillai, S. C.; Periyat, P.; George, R.; McCormack, D. E.; Seery, M. K.; Hayden, H.; Colreavy, J.; Corr, D.; Hinder, S. J. J. Phys. Chem. C 2007, 111, 1605-1611.

(21) Sato, S.; Nakamura, R.; Abe, S. Appl. Catal., A 2005, 284, 131

(22) Mwabora, J. M.; Lindgren, T.; Avendano, E.; Jaramillo, T. F.; Lu, J.; Lindquist, S. E.; Granqvist, C. G. J. Phys. Chem. B 2004, 108, 20193. crystallizations of anatase-rutile heterojunctions and nitrogen doping were achieved using EDTA. Nishide et al. studied the crystal structure and optical properties of $\mathrm{TiO}_{2}$ materials prepared from Ti-EDTA complexes. ${ }^{23} \mathrm{High}$ photocatalytic activities of anatase-brookite and anatasecarbon nanotubes heterojunctions have also been reported. ${ }^{24,25}$ However, to the best of our knowledge, there is no systematic study available on a highly visible light active $\mathrm{TiO}_{2-x} \mathrm{~N}_{x}$ anatase-rutile heterojunction photocatalysts. The current study focuses on the low temperature crystallization, mechanism of formation, and the photocatalytic activity of $\mathrm{TiO}_{2-x} \mathrm{~N}_{x}$ heterojunctions.

\section{Experimental Methods}

2.1. Synthesis of N-Doped Titania Heterojunctions. All reagents were used without further purification. Titanium isopropoxide (Aldrich 97\%) and EDTA (Aldrich 99.99\%) was used as the titania precursor and modifier respectively. In a typical synthesis for 1:1 EDTA modified sample, titanium isopropoxide $(9 \mathrm{~mL})$ was dissolved in isopropanol $(23 \mathrm{~mL})$. This solution was mixed with glacial acetic acid $(1.7 \mathrm{~mL})$ and EDTA $(8.8 \mathrm{~g})$. The precipitate obtained was then mixed with deionized water $(55 \mathrm{~mL})$ and stirred for $2 \mathrm{~h}$ to form a sol. The sol obtained was then heated in an oven at $80^{\circ} \mathrm{C}$ to form a solution, which on further heating converts to a gel. Xerogel thus obtained after $24 \mathrm{~h}$ was calcined at $400,500,600,700,800$, and $900{ }^{\circ} \mathrm{C}$ for $2 \mathrm{~h}$ at a heating rate of $10{ }^{\circ} \mathrm{C} / \mathrm{min}$. Various molar ratios of TTIP/IPA/ $\mathrm{ACOH} / \mathrm{H}_{2} \mathrm{O} /$ EDTA were used for the synthesis of different samples (Supporting Information 15). All nitrogen doped heterojunctions were prepared by successively replacing 0.5 molar ratios of acetic acid by EDTA (identified as $0.5 \mathrm{ED}-\mathrm{TiO}_{2}, 1.0 \mathrm{ED}^{-\mathrm{TiO}_{2}}$, $1.5 \mathrm{ED}^{-\mathrm{TiO}_{2}}$, and $2.0 \mathrm{ED}-\mathrm{TiO}_{2}$ respectively after calcination). Ratios between other reagents were maintained as constant in all synthesis. The control sample without EDTA was also prepared using the same synthesis method. Molar ratio between titanium isopropoxide, acetic acid, isopropanol, and water was 1:2:10:100 for the synthesis of the control sample. Degussa P-25 was used as the standard $\mathrm{TiO}_{2}$ sample for comparison.

2.2. Characterization Techniques. The FTIR spectra of xerogel dried at $100{ }^{\circ} \mathrm{C}$ and calcined at different temperatures were recorded using a Perkin-Elmer GX-FTIR spectrometer in the range $4000-400 \mathrm{~cm}^{-1}$. Transparent pellets were prepared using a $4 \mathrm{~mm}$ dye after mixing samples with $\mathrm{KBr}$. Rheometric Scientific DSC QC and Shimadzu DTG-60 instruments were used for differential scanning calorimetry (DSC) and differential thermal analysis (DTA) respectively. In both cases, about $5 \mathrm{mg}$ of dried gel was heated from room temperature $\left(25^{\circ} \mathrm{C}\right)$ to $600{ }^{\circ} \mathrm{C}$ at a constant heating rate of $10{ }^{\circ} \mathrm{C} / \mathrm{min}$. The crystal phases of calcined samples were analyzed by X-ray diffraction using a Siemens D500 X-ray diffractometer $\left(2 \theta=10-70^{\circ}\right)$ working with $\mathrm{Cu}-\mathrm{K} \alpha$ radiation $(\lambda=0.15418 \mathrm{~nm})$. The Spurr equation (eq 1) was employed for the precise calculation of the amount of rutile in the sample.

$$
F_{R}=\frac{1}{1+0.8\left[I_{A}(101) / I_{R}(110)\right]}
$$

(23) Nishide, T.; Sato, M.; Hara, H. J. Mater. Sci. 2000, 35, 465-469.

(24) Tian, G.; Fu, H.; Jing, L.; Xin, B.; Pan, K. J. Phys. Chem. C 2008, 112, 3083-3089.

(25) Wang, H.; Quan, X.; Yu, H.; Chen, S. Carbon 2008, 46, 112 61132 . 
Where $F_{R}$ is the mass fraction of rutile, $I_{A}\left(\begin{array}{lll}1 & 0 & 1\end{array}\right)$ and $I_{R}\left(\begin{array}{lll}1 & 1 & 0\end{array}\right)$ are the integrated main peak intensities of anatase and rutile, respectively. Crystallite sizes of anatase and rutile in calcined samples were calculated using the Scherrer equation (eq 2).

$$
\Phi=\frac{k \lambda}{\beta \cos \theta}
$$

Where $\Phi$ is the crystallite size, $k$ is the shape factor, $\lambda$ is the X-ray radiation wavelength, and $\beta$ the full line width at half-maximum height of the main intensity peak after subtraction of the equipment line broadening. Raman spectra of all samples were recorded at room temperature with a Dilor ISA Labram 1 B microRaman system equipped with a $514 \mathrm{~nm} \mathrm{Ar}^{+}$ion laser (Laser Physics Reliant 150 Select Multi-Line). Measurements were carried out on powder samples at a laser power of $3 \mathrm{~mW}$ to avoid excessive heating.

X-ray photoelectron spectroscopy (XPS) analyses were performed on a Thermo VG Scientific Sigma Probe spectrometer using monochromatic $\mathrm{Al}-\mathrm{K} \alpha$ radiation (photon energy 1486.6 $\mathrm{eV}$ ). For Ti 2 p high-resolution spectra pass energy of $20 \mathrm{eV}$ and a $0.1 \mathrm{eV}$ step size were used. A pass energy of $50 \mathrm{eV}$ and a step size of $0.2 \mathrm{eV}$ were used for $\mathrm{N}$ 1s high-resolution spectra. Charge compensation was achieved by using a low-energy electron flood gun. Quantitative surface chemical analyses were calculated from the high-resolution core level spectra, following the removal of a nonlinear Shirley background. Absorbance spectra of the samples were recorded in the diffuse reflectance mode (with an integrated sphere attachment) using a Perkin-Elmer Lambda $900 \mathrm{UV} / \mathrm{vis} / \mathrm{NIR}$ spectrometer, using $\mathrm{BaSO}_{4}$ as the reference sample (in the range of 300-600 nm). Sample pellets were prepared using a $4 \mathrm{~mm}$ die after thoroughly mixing the powder samples with $\mathrm{KBr}$. The band gaps were calculated by extrapolating the lower wavelength cutoff region. Samples for photoluminescence studies were prepared by dispersing as prepared powders $(0.01 \mathrm{~g}$ in $100 \mathrm{~mL})$ in deionized water. All samples were sonicated for $30 \mathrm{~min}$ before analysis. Room temperature emission spectra of samples were obtained from Perkin-Elmer Luminescence Spectrometer (LS-55) at an excitation wavelength of $260 \mathrm{~nm}$ in the range 300 to $800 \mathrm{~nm}$.

Nitrogen adsorption and desorption isotherms were collected at liquid nitrogen temperature using a Quantachrome 2000e surface area analyzer. All samples were degassed at $300{ }^{\circ} \mathrm{C}$ for $2 \mathrm{~h}$ under vacuum prior to the analysis. The specific surface area was calculated using the linear portion of the BrunauerEmmett-Teller (BET) model $\left(P / P_{0}=0.05-0.2\right)$. Desorption branch of the Barret-Joyner-Halenda (BJH) model was employed for the precise determination of pore diameter and volumes. For transmission electron microscopy (TEM) analysis, powder samples were suspended in water and sonicated for 30 min before being dispersed onto Formvar-coated copper grids. The particle-loaded grids were studied under JEOL JEM2100 transmission electron microscope operating at an accelerating voltage of $200 \mathrm{kV}$.

2.3. Photocatalysis Study. Decomposition of methylene blue was performed to evaluate the photocatalytic activities of samples. The catalyst $(0.06 \mathrm{~g})$ was dispersed in an aqueous solution of methylene blue $\left(50 \mathrm{~mL} 1 \times 10^{-5} \mathrm{M}\right)$ placed in a glass vessel $(100 \mathrm{~mL})$. The vessel was placed in the dark for $30 \mathrm{~min}$ and irradiated with visible light $\left(0.68 \mathrm{~W} / \mathrm{m}^{2}\right)$ using Q-Sun solar simulator and a primary blue filter $(450 \mathrm{~nm})$ (Supporting Information 13). The temperature of the suspension was maintained at $25{ }^{\circ} \mathrm{C}$ with the help of an air cooler (thermostat attached) connected to the solar simulator. Degradation of methylene blue

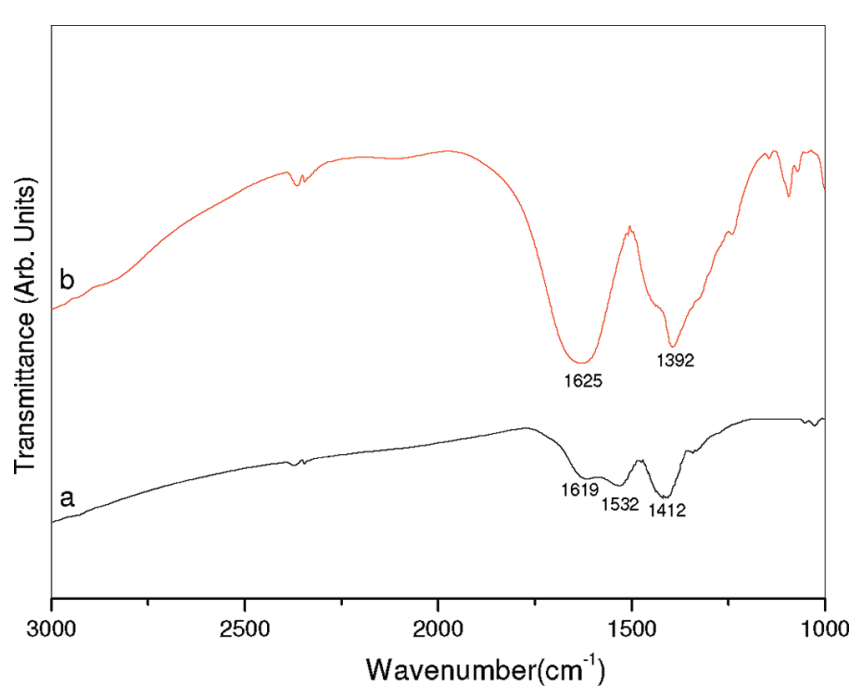

Figure 1. FT-IR Spectrum of $80^{\circ} \mathrm{C}$ dried titania precursor (a) acetic acid modified and (b) EDTA modified.

was monitored by taking aliquots at equal time intervals of $1 \mathrm{~h}$. These aliquots were centrifuged, and absorption spectra of the samples were recorded using Perkin-Elmer Lambda 900 UV/vis/ NIR spectrometer. Similar experiments were carried out for samples calcined at different temperatures. The rate of degradation was assumed to obey pseudo-first order kinetics, given that natural logarithmic plots were linear. The rate constant for degradation, $k$, was calculated from the first order plot (eq 3).

$$
\ln \left(\frac{A_{0}}{A}\right)=k t
$$

Where $A_{0}$ is the initial absorbance, $A$ is absorbance after a time $(t)$, and $k$ is the first order rate constant. All photocatalytic experiments were triplicated, and the rate constants were within $5 \%$ error limit.

\section{Results and Discussion}

3.1. Characterization of Modified Precursor. 3.1.1. FT-IR Spectral Studies. The nature of reaction intermediates formed from acetic acid and EDTA modified titania precursor was investigated using FT-IR spectroscopy. Formation of an ionic Ti-EDTA complex responsible for the low temperature crystallization of heterojunctions was observed from this study. The difference in frequency $\Delta v$ between antisymmetric and symmetric vibrations of $\mathrm{C}=\mathrm{O}$ bonds are usually related to the type of coordination (Figure 1) in metal carboxylates. ${ }^{26}$ Acetic acid modified gel exhibits characteristic antisymmetric and symmetric $\mathrm{C}=\mathrm{O}$ stretching vibrations at 1532 and $1412 \mathrm{~cm}^{-1}$, respectively. ${ }^{27,28}$ The $\Delta v$ value of $120 \mathrm{~cm}^{-1}$ observed is characteristic of a bridged acetic acid titanium isopropoxide complex as reported by Sanchez et al. ${ }^{28}$ Antisymmetric and symmetric $\mathrm{C}=\mathrm{O}$ stretching vibrations of EDTA modified

(26) Mehrotra, R. C.; Bohra, R. Metal Carboxylates; Academic Press: London, 1983; p 48.

(27) Perrin, F. X.; Nguyen, V.; Vernet, J. L. J. Sol-Gel Sci. Technol. 2003, 28, 205-215.

(28) Doeuff, S.; Henry, M.; Sanchez, C.; Livage, J. J. Non-Cryst. Solids 1987, 89, 206-216. 


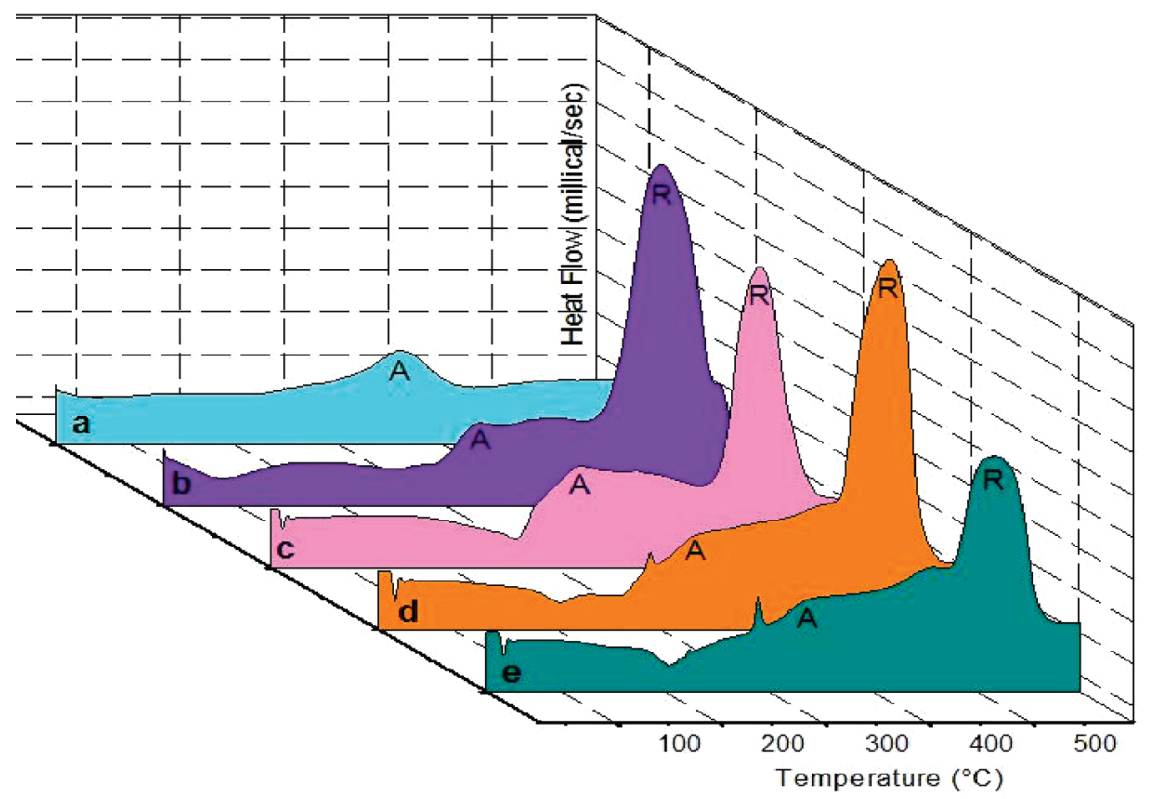

gel were found at 1625 and $1392 \mathrm{~cm}^{-1}$, respectively. The $\Delta v$ value of $233 \mathrm{~cm}^{-1}$ observed for the EDTA modified gel confirmed the monodentate and ionic behavior of COO group in the complex. ${ }^{29}$ The spectrum of this complex was consistent with that of $\left[\mathrm{Ti}\left(\mathrm{H}_{2} \mathrm{O}\right)\right.$ (edta) $]$ as observed by Sato et al. ${ }^{30}$

All EDTA modified samples showed identical FT-IR spectra. The formation of the acetic acid bridged complex was not observed in compositions containing both acetic acid and EDTA. These results indicate a preferential formation of the $\left[\mathrm{Ti}\left(\mathrm{H}_{2} \mathrm{O}\right)\right.$ (edta)] complex from a mixture of acetic acid, EDTA, and titanium tetraisopropoxide, which can be correlated to the stronger ligand character of EDTA. Variations of ionic character among the different EDTA modified compositions were also investigated. An increase of ionic character was observed as a decrease in antisymmetric stretching frequency values of $\mathrm{C}=\mathrm{O}$ group (Supporting Information 1). A minimum antisymmetric value of $1600 \mathrm{~cm}^{-1}$ observed for 1:1 EDTA complex indicates it is of the highest ionic character, leading to a lowest thermal stability. This was later confirmed by the completion of phase transformation to rutile at $700{ }^{\circ} \mathrm{C}$ (From XRD). Bridged acetate groups in the acetic acid complex effectively alter the condensation pathway and promote the formation of linear polymers. This leads to the formation of anatase titania at higher temperatures, whereas EDTA complex exists as monomers resulting in the low temperature crystallization of anatase and rutile. These results thus confirmed the formation of a high temperature stable covalent acetic acid complex and a thermally less stable ionic EDTA complex of $\mathrm{Ti}^{4+}$ (Supporting Information 2).

3.1.2. Thermal Stability Analysis of Modified Precursor. Both the amorphous to anatase transition and the anatase-rutile transformation (ART) from acetic acid and

(29) Sawyer, D. T.; MCKinnie, M. Inorg. Chem. 1960, 82, 4191-4196.

(30) Sato, M.; Hara, H.; Nishide, T.; Sawada, Y. J. Mater. Chem. 1996, 6(11), 1767-1770.
EDTA derived complexes of titania were analyzed using differential scanning calorimetry (DSC) and thermogravimetric analysis (TGA) techniques. For both samples, evaporation of water and acetic acid molecules from the gel was observed as an endothermic DSC peak at $50{ }^{\circ} \mathrm{C}$ (Figure 2). The acetic acid complex showed only one exothermic peak at $360{ }^{\circ} \mathrm{C}$ representing the crystallization of anatase phase. Anatase to rutile transformation was not observed for this complex up to $600{ }^{\circ} \mathrm{C}$. Removal of coordinated water molecules from the EDTA complexes were observed as an endothermic peak at $265^{\circ} \mathrm{C}$. Since there are no such coordinated water molecules in acetic acid complex, a corresponding peak was not observed in these samples. Among the different EDTA complexes, the most ionic (1:1 EDTA) material shows the lowest anatase and rutile crystallization temperatures of 320 and $498^{\circ} \mathrm{C}$ respectively. Slight increases in both temperatures were observed for complexes containing excess EDTA (1:1.5 and 1:2). This may be due to the hindering effect of excess EDTA toward anatase phase evolution and its transformation to rutile. An additional exotherm responsible for the decomposition of unreacted EDTA was also observed at $290{ }^{\circ} \mathrm{C}$ in complexes containing excess EDTA $(1: 1.5$ and $1: 2){ }^{31}$ The formation of anatase-rutile heterojunctions were observed only from EDTA modified titania precursor. In contrast, acetic acid modified precursor shows higher thermal stability. It is thus clear that in the case of EDTA modified samples, amorphous to crystalline as well as anatase to rutile transformations happened at lower temperatures.

The total weight loss calculated for the acetic acid modified complex from the TGA curve was $17 \%$. An increased weight loss of $58 \%$ and $85 \%$ was observed for $1: 0.5$ and 1:2.0 EDTA modified compositions respectively

(31) Guinesi, L. S.; Ribeiro, C. A.; Crespi, M. S.; Santos, A. F.; Capela, M. V. J. Therm. Anal. Calorim. 2006, 85, 301-307. 


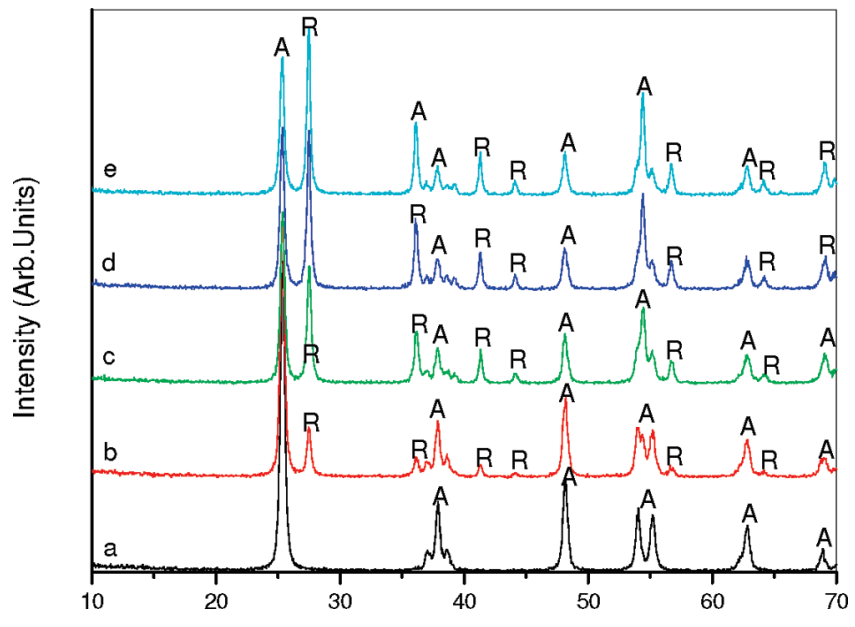

Figure 3. XRD of samples calcined at $600{ }^{\circ} \mathrm{C}$. (a) Control $\mathrm{TiO}_{2}$, (b) 0.5 ED-TiO ${ }_{2}$, (c) $1.0 \mathrm{ED}_{-} \mathrm{TiO}_{2}$, (d) $1.5 \mathrm{ED}-\mathrm{TiO}_{2}$, (e) $2.0 \mathrm{ED}-\mathrm{TiO}_{2}$ (A = anatase; $\mathrm{R}=$ rutile).

(Supporting Information 3). The weight losses for the acetic acid complex happen in the range $30-250{ }^{\circ} \mathrm{C}$ and $300-500{ }^{\circ} \mathrm{C}$ because of the evaporation of solvents and the decomposition of the complex into crystalline anatase titania. On the other hand, the EDTA complex decomposes in three steps $\left(30-150,250-450,530-600{ }^{\circ} \mathrm{C}\right)$, a process corresponding to evaporation of solvents, decomposition of EDTA-titania complex in to anatase titania, and anatase-rutile transformation, respectively. On increasing the amount of EDTA, a significant increased weight loss in the anatase formation step was observed, which can be due to the decomposition of excess EDTA present in these samples. The lowering of both the anatase and rutile formation temperature was also observed (from the TGA curve) on increasing the amount of EDTA.

3.2. Formation of N-Doped Heterojunctions. 3.2.1. $X$-ray Diffraction Studies. X-ray diffraction patterns recorded from samples calcined at different temperatures confirmed the high temperature stability of acetic acid modified samples and low temperature crystallization of N-doped anatase-rutile heterojunctions from EDTA modified samples. The control sample showed only the peaks characteristic of anatase phase up to $600{ }^{\circ} \mathrm{C}$ (Figure 3), whereas all EDTA modified samples exist as anatase-rutile mixtures at a temperature as low as $500{ }^{\circ} \mathrm{C}$. The crystallization of anatase-rutile heterojunctions were observed even at $400^{\circ} \mathrm{C}$ for $1: 1$ and 1:1.5 EDTA modified samples (Figure 4). Complete rutile formation for the 1:1 EDTA modified sample (which was found to be the most ionic from FT-IR studies) was observed at $700{ }^{\circ} \mathrm{C}$ (Supporting Information 4). Compared to other EDTA modified samples, 1:2.0 modified EDTA sample shows slow anatase rutile transformation kinetics and contains $4 \%$ anatase even at $800{ }^{\circ} \mathrm{C}$. All samples calcined at $900{ }^{\circ} \mathrm{C}$ exist as 100\% rutile (Supporting Information 5). Bridged acetate groups in AcOH-Ti complex effectively alter the condensation pathway and promote the formation of linear polymers. This leads to the formation of anatase titania at higher temperatures, whereas EDTA-Ti complex

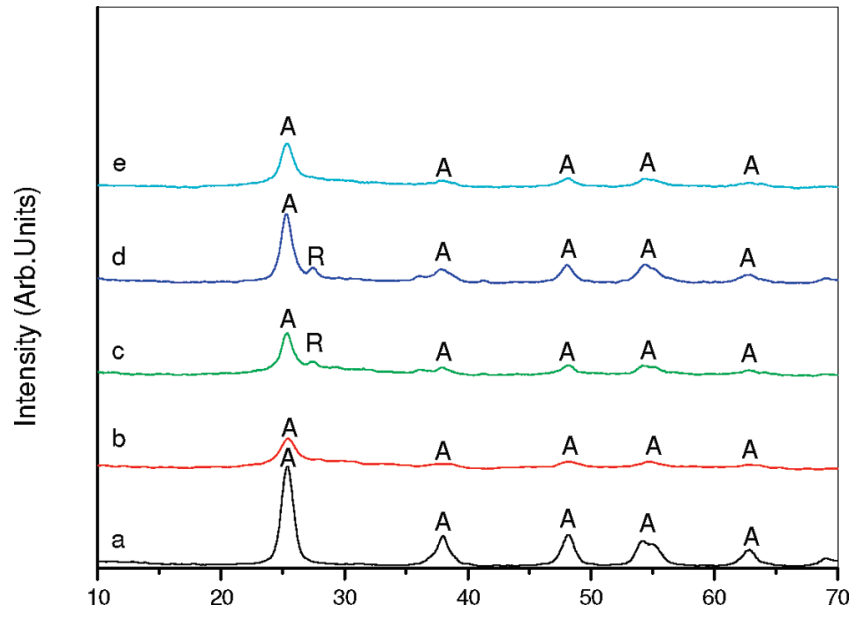

Figure 4. $\mathrm{XRD}$ of samples calcined at $400{ }^{\circ} \mathrm{C}$. (a) Control $\mathrm{TiO}_{2}$, (b) 0.5 ED-TiO 2 , (c) 1.0 ED-TiO ${ }_{2}$,(d) 1.5 ED-TiO 2 , (e) 2.0 ED-TiO 2 (A = anatase; $\mathrm{R}=$ rutile).

exists as monomers and results in the low temperature crystallization of both anatase and rutile phases having large crystallite sizes. Slight changes $\left(2 \theta=0.2^{\circ}\right)$ in the anatase 110 peak positions for EDTA modified titania samples were observed even at $400{ }^{\circ} \mathrm{C}$ compared to the control sample (Supporting Information 6), which results from changes in the lattice parameters as a result of nitrogen doping. ${ }^{32}$ Thus XRD results revealed the low temperature crystallization of anatase rutile heterojunctions from EDTA modified titania samples and successful lattice incorporation of nitrogen.

3.2.2. Raman Studies. Raman spectroscopy, a more surface sensitive technique was employed as an additional tool to confirm phase composition and surface homogeneity. ${ }^{33}$ The Raman active modes for anatase $\left(\mathrm{A}_{1 \mathrm{~g}}+\right.$ $2 \mathrm{~B}_{1 \mathrm{~g}}+3 \mathrm{E}_{\mathrm{g}}$ at $147,197,396,516$, and $\left.638 \mathrm{~cm}^{-1}\right)$ and rutile $\left(\mathrm{A}_{1 \mathrm{~g}}+\mathrm{B}_{1 \mathrm{~g}}+\mathrm{B}_{2 \mathrm{~g}}+\mathrm{E}_{\mathrm{g}}\right.$ at $144,238,447$, and $\left.611 \mathrm{~cm}^{-1}\right)$ were used as fingerprints. ${ }^{34-36}$ The samples 1:1 EDTA and 1:1.5 EDTA calcined at $400^{\circ} \mathrm{C}$ has peaks characteristic of anatase rutile mixtures, while other samples show peaks of pure anatase phase (Supporting Information 7). Only the acetic acid modified sample gives peaks of anatase at $600{ }^{\circ} \mathrm{C}$; all EDTA modified samples were anatase-rutile mixtures (Figure 5). All samples calcined at $900^{\circ} \mathrm{C}$ shows peaks at $144,611,447$, and $238 \mathrm{~cm}^{-1}$, which confirmed the existence of $100 \%$ rutile phase (Supporting Information 8). Thus the results observed from X-ray diffraction studies were further confirmed by Raman spectroscopy.

3.2.3. FT-IR Spectral Studies. Spectra of heterojunctions obtained were highly dependent on the processing temperature and nature of dopant species (Figure 6). Considerable shifting of $\mathrm{Ti}-\mathrm{O}-\mathrm{Ti}$ stretching frequencies to higher energy was observed for $\mathrm{N}$-doped samples in comparison to the undoped one. At $400{ }^{\circ} \mathrm{C}, \mathrm{Ti}-\mathrm{O}-\mathrm{Ti}$ stretching peak of $\mathrm{N}$-doped sample was observed at a

(32) Zhang, Q.; Gao, L. J. Eur. Ceram. Soc. 2006, 26, 1535-1545.

(33) Gao, K. Phys. B 2007, 398, 33-37.

(34) Ohsaka, T.; Izumi, F.; Fujiki, Y. J. Raman Spectrosc. 1978, 7, 321.

(35) Berger, H.; Tang, H.; Lévy, F. J. Cryst. Growth 1993, 130, 108.

(36) Tang, H.; Prasad, K.; Sanjines, R.; Schmid, P. E.; Levy, F. J. Appl. Phys. 1994, 75, 2042. 


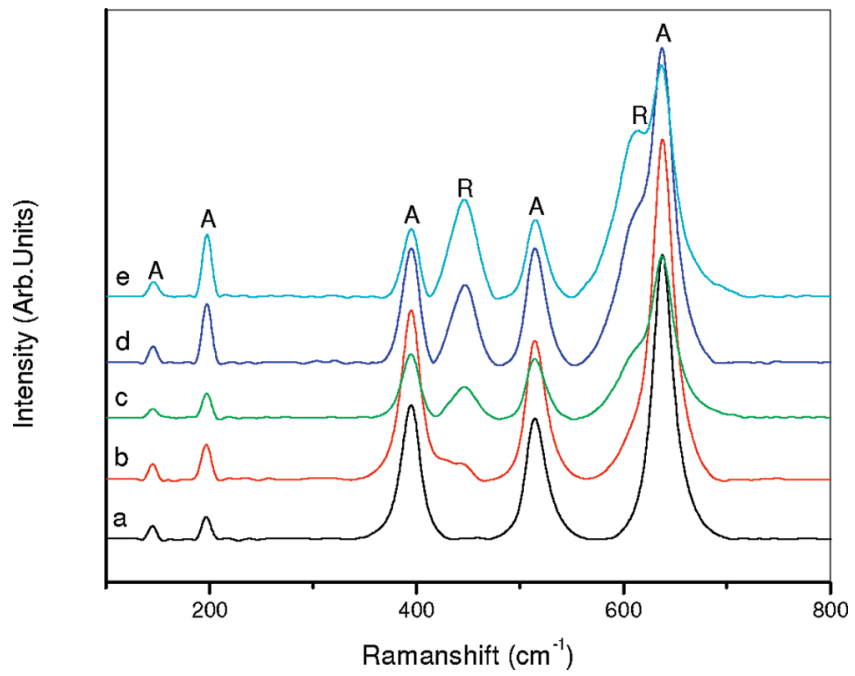

Figure 5. Raman spectra of samples calcined at $600^{\circ} \mathrm{C}$. (a) Control $\mathrm{TiO}_{2}$, (b) $0.5 \mathrm{ED}-\mathrm{TiO}_{2}$, (c) $1.0 \mathrm{ED}-\mathrm{TiO}_{2}$, (d) $1.5 \mathrm{ED}-\mathrm{TiO}_{2}$, (e) $2.0 \mathrm{ED}^{-\mathrm{TiO}_{2}}$.

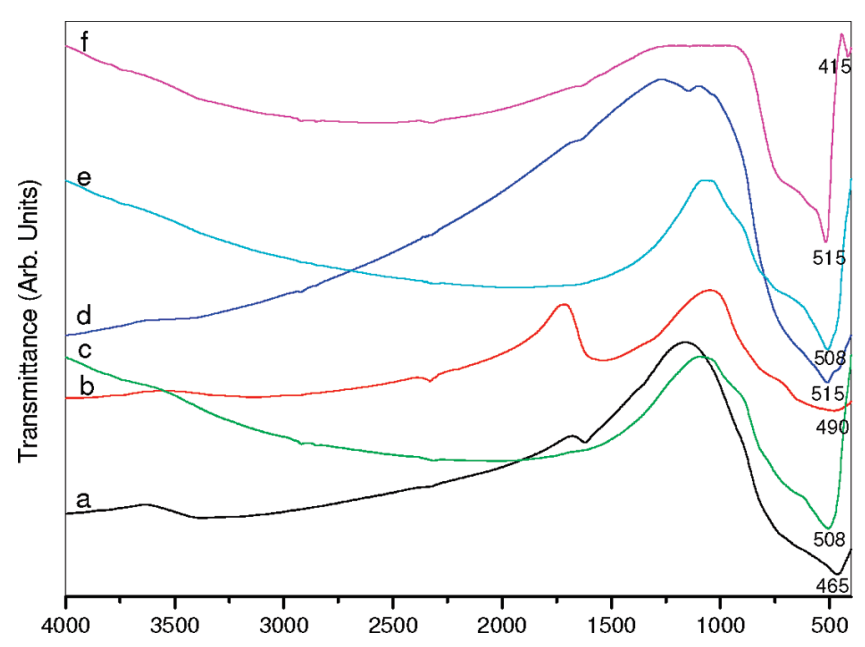

Figure 6. FT-IR Spectrum of calcined titania. (a) Control $\mathrm{TiO}_{2} 400$, (b) $0.5 \mathrm{ED}-\mathrm{TiO}_{2}$ 400, (c) Control $\mathrm{TiO}_{2} 600$, (d) $0.5 \mathrm{ED}-\mathrm{TiO}_{2}$ 600, (e) Control $\mathrm{TiO}_{2} 700$, (f) $0.5 \mathrm{ED}-\mathrm{TiO}_{2} 700$.

higher energy of $508 \mathrm{~cm}^{-1}$ compared to $465 \mathrm{~cm}^{-1}$ for undoped one. Similar shift in $\mathrm{Ti}-\mathrm{O}-\mathrm{Ti}$ stretching energies were also observed for samples calcined at higher temperatures. These types of shifts to higher energies were previously reported and assigned to the formation of $\mathrm{O}-\mathrm{Ti}-\mathrm{N}$ and $\mathrm{N}-\mathrm{Ti}-\mathrm{N}$ bonds in $\mathrm{N}$-doped titania. ${ }^{37}$ Since we observed the formation of $\mathrm{N}-\mathrm{Ti}-\mathrm{N}$ bonds as an additional peak at $415 \mathrm{~cm}^{-1}$ in samples calcined at $700{ }^{\circ} \mathrm{C},{ }^{37}$ shifting observed for $\mathrm{Ti}-\mathrm{O}-\mathrm{Ti}$ stretching energies below this temperature can be assigned to the formation of $\mathrm{O}-\mathrm{Ti}-\mathrm{N}$ bonds through partial replacement of oxygen. No evidence for interstitial nitrogen doping and other nitrogen impurities were observed from the spectra. The lattice incorporation of nitrogen in two different forms was thus observed from FT-IR results. Formations of $\mathrm{O}-\mathrm{Ti}-\mathrm{N}$ and $\mathrm{N}-\mathrm{Ti}-\mathrm{N}$ bonds were also confirmed through XPS studies and will be discussed in the following section.

(37) Jackson, A. W.; Shebanova, O.; Hector, A. L.; McMillan, P. F. J. Solid State Chem. 2006, 179, 1383-1393.

3.2.4. XPS Studies. XPS results revealed two types of lattice doping $(\mathrm{O}-\mathrm{Ti}-\mathrm{N}$ and $\mathrm{N}-\mathrm{Ti}-\mathrm{N})$ and a decrease of nitrogen content with an increase of EDTA concentration (Supporting Information 9). An increase of EDTA concentration accelerates crystallite growth (from XRD results), which can decrease the amount $\mathrm{N}$-doping as a result of surface and lattice strain relaxation. Decrease of nitrogen content was also observed with an increase of calcination temperature. This can be due to the crystallite growth and escape of the dopant species formed through the decomposition of Ti-EDTA complex at higher temperatures. The $\mathrm{N}$ 1s binding energy peak of $\mathrm{N}$-doped $\mathrm{TiO}_{2}$ heterojunctions were found to be highly depends on the calcination temperature. In the case of samples calcined at $700{ }^{\circ} \mathrm{C}$, formation of $\mathrm{N}-\mathrm{Ti}-\mathrm{N}$ bonds were observed as a peak at $396 \mathrm{eV}$ (which corresponds to an additional FTIR peak at $415 \mathrm{~cm}^{-1}$ ) (Figure $7 \mathrm{~b}$ ). ${ }^{38}$ This can be due to the formation of specific $\mathrm{Ti}-\mathrm{N}$ bonds through an oxygen vacancy compensation mechanism at a higher temperature. Only one peak was observed at $400.1 \mathrm{eV}$ in samples calcined at $600{ }^{\circ} \mathrm{C}$ (Figure 7 a), which is a value greater than the typical $\mathrm{N}$ 1s binding energy of $397.2 \mathrm{eV}$ in TiN. ${ }^{39}$ Since FT-IR and XRD results indicate lattice doping, this peak therefore can be attributed to the 1 s electron binding energy of the $\mathrm{N}$ atom in the environment of $\mathrm{O}-\mathrm{Ti}-\mathrm{N}$ in lattice $\mathrm{N}$-doped titania. The binding energy shifting can be understood by the fact that the $\mathrm{N} 1$ s electron binding energy is higher when the formal charge of $\mathrm{N}$ is more positive (e.g., $408 \mathrm{eV}$ in $\mathrm{NaNO}_{3}$ ), compared to zero or a negative formal charge $\left(398.8 \mathrm{eV}\right.$ in $\left.\mathrm{NH}_{3}\right){ }^{39,40}$ When a nitrogen substitutes for the oxygen in the initial $\mathrm{O}-\mathrm{Ti}-\mathrm{O}$ structure, the electron density around $\mathrm{N}$ is reduced compared to that in a TiN crystal (because of the $\mathrm{O}$ atom on the $\mathrm{Ti}$ atom). Thus the $\mathrm{N}$ 1s binding energy in an $\mathrm{O}-\mathrm{Ti}-\mathrm{N}$ environment $(400.1 \mathrm{eV})$ is higher than that in an $\mathrm{N}-\mathrm{Ti}-\mathrm{N}$ environment $(396 \mathrm{eV})$ where the $\mathrm{N}$ atom replaces the $\mathrm{O}$ atom. These observations are consistent with the earlier XPS characterization results associated with the oxidation of TiN surfaces by Saha and Tomkins. ${ }^{39}$

As reported by Saha and Tomkins, pure titania sample has a typical Ti $2 p$ binding energy of $459.4 \mathrm{eV} .{ }^{39} \mathrm{~A} \mathrm{dec}-$ rease of 0.35 and $0.96 \mathrm{eV}$ in $\mathrm{Ti} 2 \mathrm{p}$ binding energy was observed for $\mathrm{N}$-doped heterojunctions obtained at 600 and $700{ }^{\circ} \mathrm{C}$, respectively, in comparison to the standard sample (Figure 8). A decrease of Ti $2 p$ binding energy is a direct measure of the lowering of the valence state level of $\mathrm{Ti}^{4+}$ to $\mathrm{Ti}^{3+}$ and $\mathrm{Ti}^{2+}$ level as a result of the lattice substitution of nitrogen for oxygen. ${ }^{35,41}$ Lattice incorporation of nitrogen creates $\mathrm{Ti}-\mathrm{N}$ bonds by the partial replacement of $\mathrm{O}^{2-}$ with $\mathrm{N}^{-}$. This results in an electron density decrease and partial reduction of $\mathrm{Ti}^{4+}$ to $\mathrm{Ti}^{3+}$ and $\mathrm{Ti}^{2+}$, which reflects as a decrease in $\mathrm{Ti} 2 \mathrm{p}$ binding

(38) Irie, H.; Watanabe, Y.; Hashimoto, K. J. Phys. Chem. B 2003, 107, 5483.

(39) Saha, N. C.; Tomkins, H. C. J. Appl. Phys. 1992, 72, 3072.

(40) Chen, X.; Burda, C. J. Phys. Chem. B 2004, 108, 15446-15449.

(41) Hashimoto, S.; Murata, A.; Sakurada, T.; Tanaka, A. J. Surf. Anal. 2002, 9,459 . 

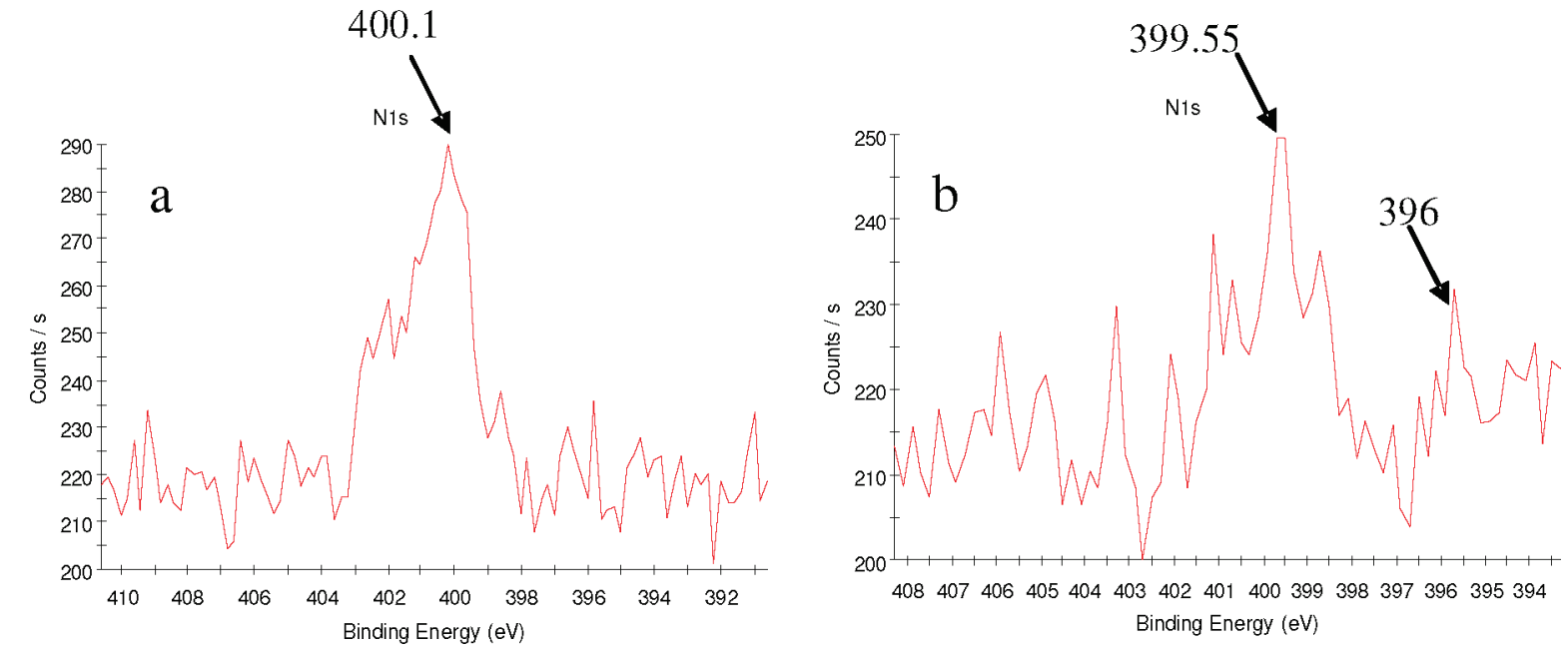

Figure 7. $\mathrm{N}$ 1s peaks in the XPS plot of calcined titania. (a) $0.5 \mathrm{ED}^{-\mathrm{TiO}_{2}} 600$, (b) $0.5 \mathrm{ED}-\mathrm{TiO}_{2} 700$.

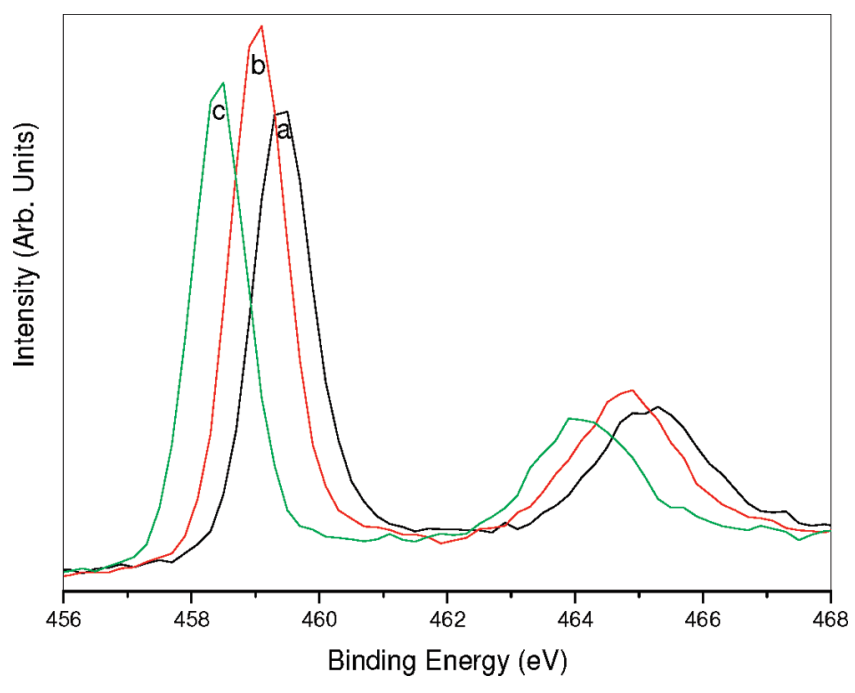

Figure 8. Ti $2 \mathrm{p}$ peaks in the XPS plot of calcined titania. (a) Control $\mathrm{TiO}_{2}$ 600 , (b) $0.5 \mathrm{ED}^{-\mathrm{TiO}_{2}} 600$, (c) $0.5 \mathrm{ED}-\mathrm{TiO}_{2} 700$.

(42) Gyorgy, E.; Pino, A. P. d.; Serra, P.; Morenza, J. L. Surf. Coat. Technol. 2003, 173, 265

(43) Rodriguez, J. A.; Jirsak, T.; Dvorak, J.; Sambasivan, S.; Fischer., D. J. Phys. Chem. B 2000, 104, 319.

(44) Sakthivel, S.; Kisch, H. Angew. Chem., Int. Ed. 2003, 42, 49084911.
Table 1. Band Gap Values of Heterojunctions Calcined at Different Temperatures

\begin{tabular}{lccc}
\hline composition & $\begin{array}{c}\text { band gap }(\mathrm{eV}) \\
400{ }^{\circ} \mathrm{C}\end{array}$ & $\begin{array}{c}\text { band gap }(\mathrm{eV}) \\
600{ }^{\circ} \mathrm{C}\end{array}$ & $\begin{array}{c}\text { band gap }(\mathrm{eV}) \\
700{ }^{\circ} \mathrm{C}\end{array}$ \\
\hline control TiO $_{2}$ & 3.11 & 3.16 & 3.15 \\
$0.5 \mathrm{ED}-\mathrm{TiO}_{2}$ & 3.03 & 3.02 & 2.98 \\
$1.0 \mathrm{ED}-\mathrm{TiO}_{2}$ & 3.00 & 3.00 & 2.96 \\
$1.5 \mathrm{ED}^{-\mathrm{TiO}_{2}}$ & 2.98 & 2.98 & 2.95 \\
$2.0 \mathrm{ED}^{-\mathrm{TiO}_{2}}$ & 3.05 & 2.97 & 2.93
\end{tabular}

unavoidable presence on all air-exposed materials. ${ }^{44}$ It is therefore clear from the above observations that the lowering of $\mathrm{Ti} 2 \mathrm{p}$ binding energies and additional $\mathrm{O} 1 \mathrm{~s}$ peak observed for $\mathrm{N}$-doped heterojunctions together with FT-IR and XRD results well explained successful lattice incorporation of nitrogen through the formation of $\mathrm{O}-\mathrm{Ti}-\mathrm{N}$ and $\mathrm{N}-\mathrm{Ti}-\mathrm{N}$ bonds.

3.2.5. UV/vis Spectroscopic Studies. Band gap values calculated through diffuse reflectance measurements also support the variations of nitrogen and rutile concentrations in heterojunctions. All N-doped heterojunctions show narrowing of the band gap in comparison to the control sample (Table 1). The narrowing effect was com-

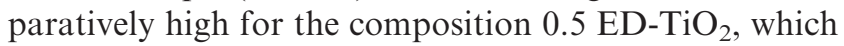
contain the highest amounts of nitrogen at each calcination temperature (Figure 9). Band gap narrowing effect was very low for compositions containing higher amounts of EDTA. This can be due to decreased N-doping as a result of excessive crystallite growth on increasing EDTA concentration. It was previously reported that the nitrogen doping can lead to a mixing of $\mathrm{N} 2 \mathrm{p}$ orbitals with $\mathrm{O} 2 \mathrm{p}$ orbitals to form intermediate energy levels and shift the absorption edge toward visible light region. ${ }^{14,45}$ Nitrogen doping also accelerate the formation of oxygen vacancies, which form additional energy levels below the conduction band. This promotes electronic excitation from the valence band to the additional energy level by absorbing visible light. ${ }^{46}$ A lowering of band gap values through

(45) Morikawa, T.; Asahi, R.; Ohwaki, T.; Aoki, K.; Taga, Y. Jpn. J. Appl. Phys. 2001, 40, L561.

(46) Yang, J.; Bai, H.; Tan, X.; Lian, J. Appl. Surf. Sci. 2006, 253, 19881994. 


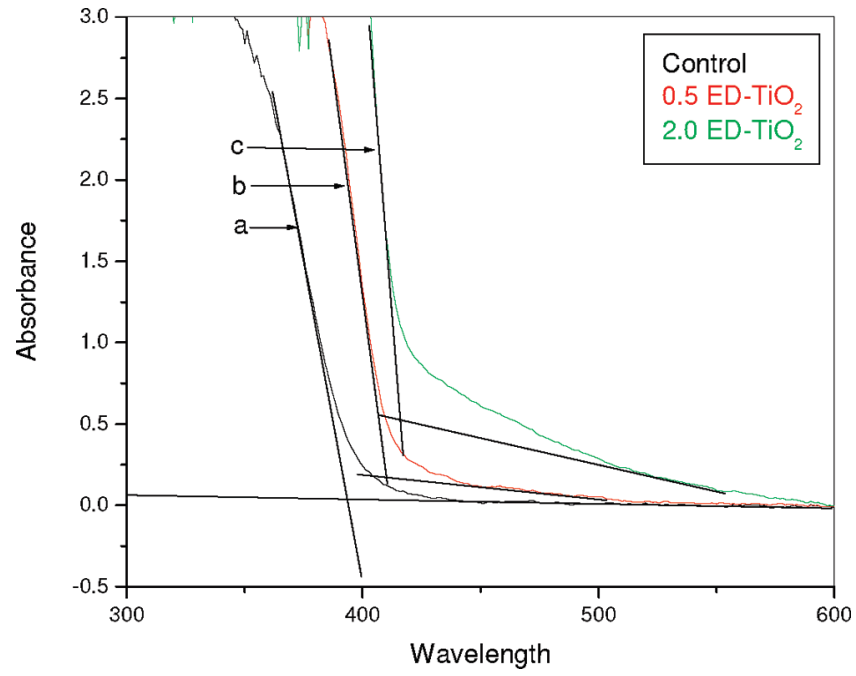

Figure 9. Diffuse reflectance spectra of (a) Control $\mathrm{TiO}_{2} 600$, (b) 0.5 ED$\mathrm{TiO}_{2} 600$, and (c) 2.0 ED-TiO 600 .

both of these mechanisms highly depends on the dopant concentration, which explains the band gap variations observed above.

The amount of rutile also plays a significant role to shift the absorption edge of heterojunctions toward the visible light region. Since it is evident from the XPS results that the amount of nitrogen decreases on increasing the EDTA content, a decrease in the band gap after the composition $0.5 \mathrm{ED}-\mathrm{TiO}_{2}$ happens mainly because of rutilation. For this reason, all samples show a decrease in the band gap on increasing the calcination temperature. At $400{ }^{\circ} \mathrm{C}$, band gap narrowing effect was low because of less rutilation at lower temperatures. The superior visible light absorbing capability of heterojunctions and their dependence on the amount of nitrogen and rutile were thus verified from diffuse reflectance results.

3.2.6. Surface Area Measurements. Isotherms of heterojunctions and the control sample show type IV characteristics with H1 type (cylindrical shape) of hysteresis (Figure 10). ${ }^{47}$ The high steepness hysteresis loop ending at a relative pressure $\left(P / P_{0}\right)$ of 0.6 is a measure of high order of mesoporosity in these samples. ${ }^{48}$ Degussa P-25, the standard photocatalyst, has a type II isotherm with small hysteresis behavior (Figure 11). This fact demonstrates the presence of a large quantity of agglomerated particles formed through a diffusion process, which decreases the porosity. Among the different samples compared, the control sample has the highest surface area $\left(134 \mathrm{~m}^{2} / \mathrm{g}\right)$ and pore volume $(0.209 \mathrm{cc} / \mathrm{g})$ at $400{ }^{\circ} \mathrm{C}$ (Table 2$)$. All heterojunction samples have lower surface area compared to the control sample at all calcination temperatures. For both heterojunctions and the control sample, a considerable decrease in surface area and pore volume was observed with an increase in calcination temperature.

(47) Nasar, R. S.; Cerqueira, M.; Longo, E.; Varela, J. A. Cerâmica 2008, 54, 38-42.

(48) Kartini, I.; Meredith, P.; Costa, J. C. D. D.; Lu, G. Q. J. Sol-Gel Sci. Technol. 2004, 31, 185-189.

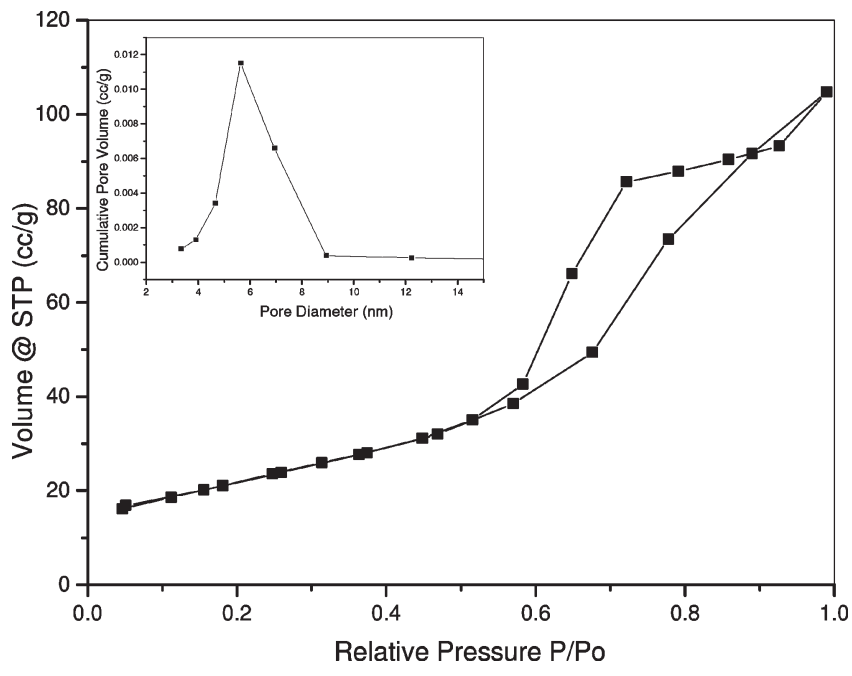

Figure 10. $\mathrm{N}_{2}$ adsorption-desorption isotherm and the pore size distribution (inset) of $1.5 \mathrm{ED}-\mathrm{TiO}_{2} 400$.

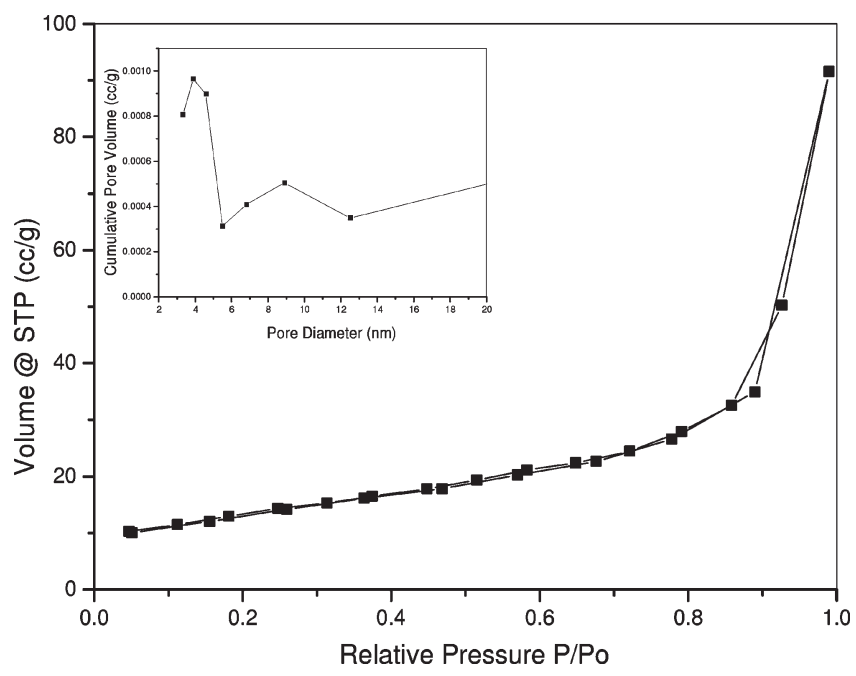

Figure 11. $\mathrm{N}_{2}$ adsorption-desorption isotherm and the pore size distribution (inset) of Degussa P-25.

Table 2. Textural Properties of Heterojunctions Calcined at Different Temperatures

\begin{tabular}{lccc}
\hline \multicolumn{1}{c}{ composition } & $\begin{array}{c}\text { surface area } \\
\left(\mathrm{m}^{2} / \mathrm{g}\right)\end{array}$ & $\begin{array}{c}\text { pore diameter } \\
(\mathrm{nm})\end{array}$ & $\begin{array}{c}\text { pore volume } \\
(\mathrm{cc} / \mathrm{g})\end{array}$ \\
\hline control 400 & 134.2 & 4.65 & 0.209 \\
control 600 & 40.06 & 8.16 & 0.104 \\
$1.5 \mathrm{ED}-\mathrm{TiO}_{2} 400$ & 79.6 & 5.64 & 0.168 \\
$1.5 \mathrm{ED}-\mathrm{TiO}_{2} 600$ & 21.28 & 8.01 & 0.052 \\
Degussa P-25 & 46.7 & 3.89 & 0.129
\end{tabular}

An increase in pore diameter was also observed with an increase in calcination temperature, which confirms the presence of interstitial pores and its grain growth. ${ }^{47}$ Among the samples calcined at $400{ }^{\circ} \mathrm{C}$, the most active catalyst $\left(1.5 \mathrm{ED}-\mathrm{TiO}_{2}\right)$ showed a larger pore diameter $(5.6 \mathrm{~nm})$ than the control sample $(4.6 \mathrm{~nm})$ because of the large grain size resulting from the thermally less stable titania precursor. The same composition has a smaller pore size at $600{ }^{\circ} \mathrm{C}$ compared to the control sample. This can be due to the densification of powder resulting from excessive grain growth. Even though the heterojunctions have poor 

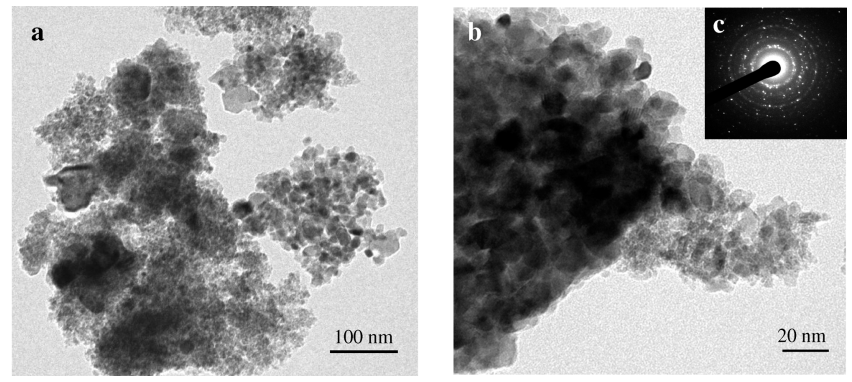

Figure 12. Transmission electron micrograph of $1.5 \mathrm{ED}^{-\mathrm{TiO}_{2}} 400$. (a) TEM, (b) HRTEM, and (c) SAED pattern.

(49) Miao, L.; Jin, P.; Kaneko, K.; Terai, A.; Nabatova-Gabain, N.; Tanemura, S. Appl. Surf. Sci. 2003, 212, 255

(50) Miao, L.; Tanemura, S.; Kondo, Y.; Iwata, M.; Toh, S.; Kaneko, K. Appl. Surf. Sci. 2004, 238, 125.
$1.5 \mathrm{ED}-\mathrm{TiO}_{2} 400$ containing $90 \%$ of $13 \mathrm{~nm}$ anatase and $10 \%$ of $18 \mathrm{~nm}$ rutile shows over 9 times more visible light activity compared to Degussa P-25 (Figure 13 a, b). Rate constants obtained for the most active catalyst and Degussa P-25 were 0.038 and $0.004 \mathrm{~min}^{-1}$, respectively (Figure 14). Significantly higher visible light activity of nitrogen doped anatase rutile heterojunctions can be explained on the basis of band gap narrowing and efficient charge separation at the anatase-rutile interface. Results obtained from XRD, FT-IR, XPS, and UV/ vis spectroscopy confirmed the formation of $\mathrm{N}$-doped anatase-rutile heterojunctions having low band gap values. Additional energy levels created as a result of efficient doping can utilize visible light for the generation of electron hole pairs. Asahi et al. explained the visible light sensitization of $\mathrm{N}$-doped $\mathrm{TiO}_{2}$ on the basis of $\mathrm{Ti}-\mathrm{N}$ bonding. Irie et al. also prepared $\mathrm{N}$-doped $\mathrm{TiO}_{2}$ by a $\mathrm{NH}_{3}$-treatment method. ${ }^{38}$ They observed the $\mathrm{N} 1 \mathrm{~s}$ peak at 396 and $400 \mathrm{eV}$ in the XPS analysis and ascribed the $396 \mathrm{eV}$ state to visible light sensitization. However, the results of Diwald et al. rather indicated a negative contribution of $\mathrm{Ti}-\mathrm{N}$ bonding to photocatalytic activity. ${ }^{51}$ So, the contribution of $\mathrm{Ti}-\mathrm{N}$ bonding to the visible-light sensitization of $\mathrm{TiO}_{2}$ has not been completely understood. In our experiments, all nitrogen doped anatase rutile mixtures at $700{ }^{\circ} \mathrm{C}$ with lower nitrogen content (containing $\mathrm{N}-\mathrm{Ti}-\mathrm{N}$ bonds) show better (except 1:0.5 ED- $\mathrm{TiO}_{2}$ ) photocatalytic activity compared to samples at $600{ }^{\circ} \mathrm{C}$ (containing $\mathrm{O}-\mathrm{Ti}-\mathrm{N}$ bonds) (Supporting Information 12). This behavior can be correlated to the formation of higher amounts of photocatalytic enhancing $\mathrm{Ti}-\mathrm{N}$ bonds at a higher temperature. The discrepancy observed in the case of 1:0.5 EDTA composition may be due to the presence of higher amounts of rutile at $700{ }^{\circ} \mathrm{C}$.

In spite of its better textural properties, the control sample was found to have very low visible light activity compared to the most active sample, which has poor textural properties but high visible light activity. It is therefore evident from the photocatalytic studies that the textural properties of catalysts are not the only factor determining the reaction kinetics. It can be concluded that the composition of heterojunctions and band gap values contribute more toward the photocatalytic activity in comparison to the textural properties.

Crystallite sizes of anatase and rutile phases were smaller for the most active heterojunction (1.5 ED-TiO 400) than that in Degussa P-25 (Supporting Information 14). This facilitates the formation of more heterojunctions and thereby increases the activity. It is known that the conduction band edge of rutile is approximately 0.2 $\mathrm{eV}$ lower than that of anatase. On this basis, the model that the photo excited electrons (from the visible midgap level) are effectively transferred from the conduction band of anatase to that of rutile has been proposed (Figure 16). When a small amount of rutile phase coexists with anatase phase, the interface between anatase and

(51) Diwald, O.; Thompson, T. L.; Goralski, E. G.; Walck, S. D.; Yates, J. T. J. Phys. Chem. B 2004, 108, 52. 

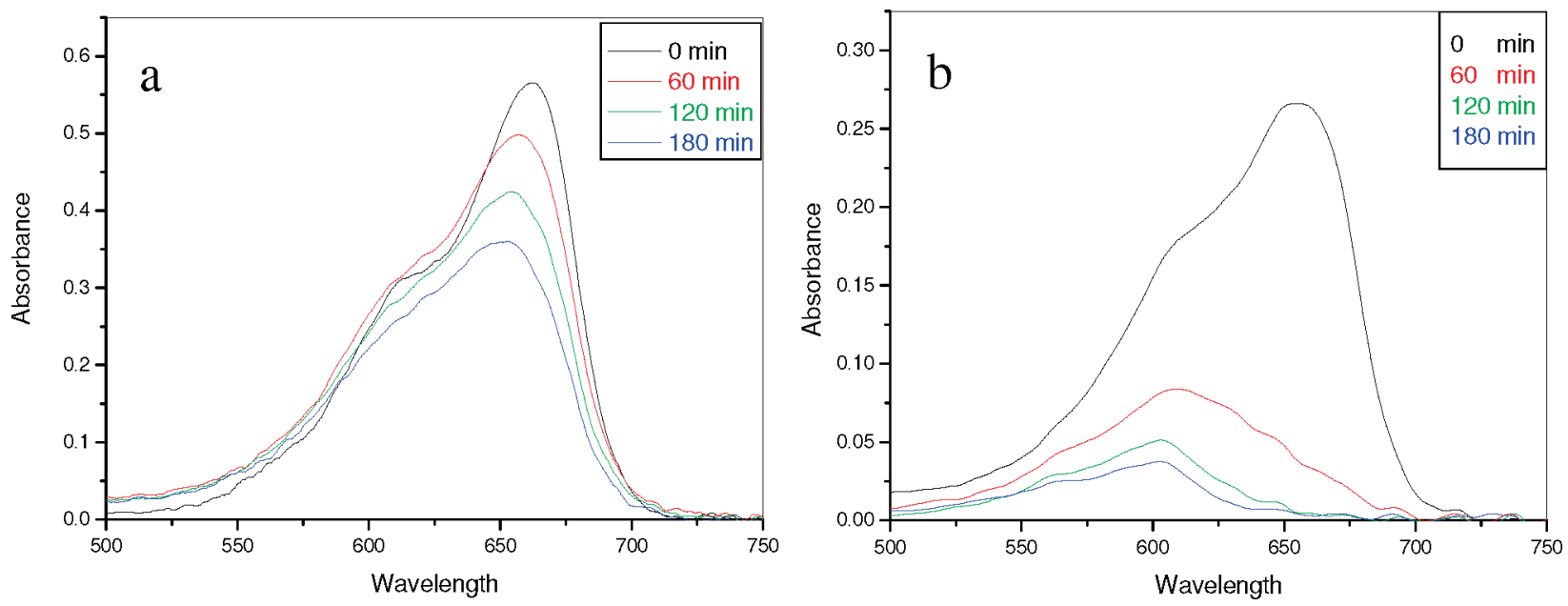

Figure 13. Absorption spectra of visible light induced methylene blue degradation using (a) Degussa P-25 and (b) $1.5 \mathrm{ED}^{-\mathrm{TiO}_{2}} 400$.

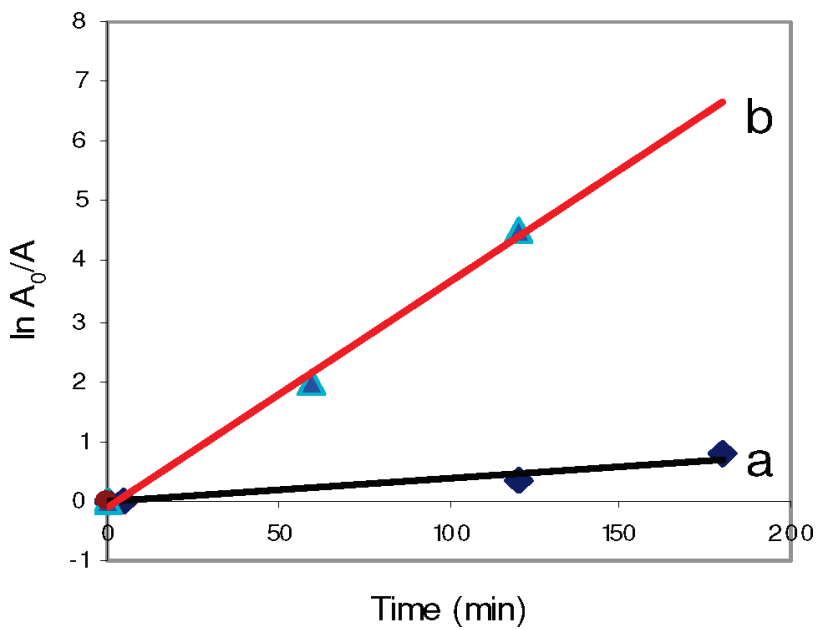

Figure 14. Kinetic study of (a) Degussa P-25 and (b) $1.5 \mathrm{ED}-\mathrm{TiO}_{2} 400$.

rutile promotes the electron transfer, and rutile works as a reaction site for photo reduction. Photo oxidation can take place either on anatase or on the rutile surface. The heterojunctions obtained at $700{ }^{\circ} \mathrm{C}$ containing more $\mathrm{Ti}-$ $\mathrm{N}$ bonds showed a higher photocatalytic activity in comparison to those obtained at $600{ }^{\circ} \mathrm{C}$. The most active heterojunction was the one obtained at $400{ }^{\circ} \mathrm{C}$, and its highest activity was found to be as a result of optimum anatase-rutile composition, nanocrystalline nature, and nitrogen doping. A decrease in photocatalytic activity was observed for heterojunctions synthesized at higher temperatures (Supporting Information 12). This can be due to the formation of a higher amount of rutile phase having higher electron hole recombination rate, and decreases in the amount of more photoactive anatase phase, nitrogen content, and surface area. Higher blue shift of methylene blue absorption peaks during the photocatalytic experiment of heterojunction samples indicates faster dye degradation through a $\mathrm{N}$-demethylation mechanism. ${ }^{52,53}$ The higher visible light photocatalytic

(52) Zhang, Y.; Xu, H.; Xu, Y.; Zhang, H.; Wang, Y. J. Photochem. Photobiol, A 2005, 170, 279.

(53) Yu, J. R.; Hoi, W. C. Environ. Sci. Technol. 2008, 42, 294-300.

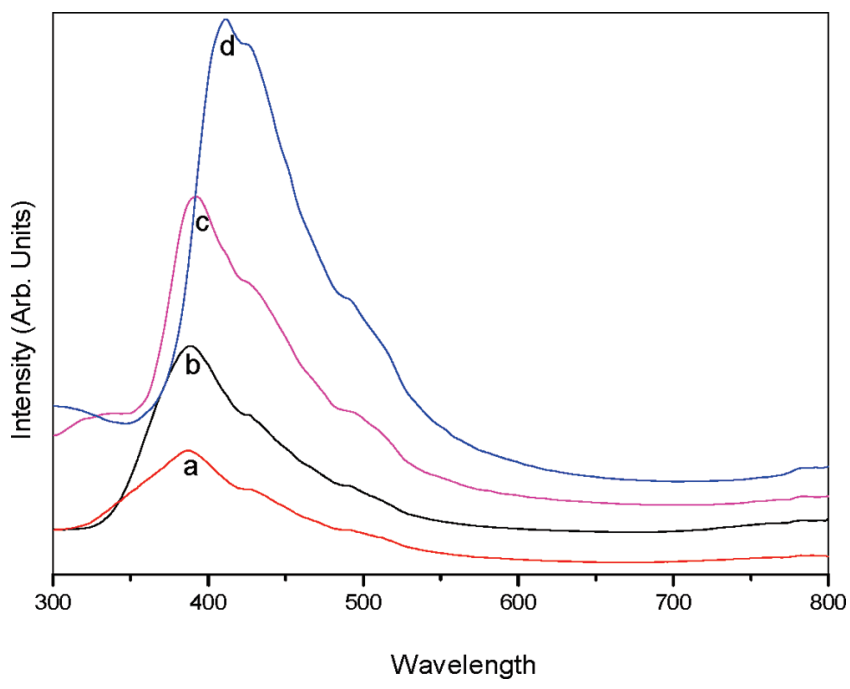

Figure 15. Photo luminescence spectra of samples (a) $1.5 \mathrm{ED}-\mathrm{TiO}_{2} 400$, (b) Degussa P-25, (c) pure anatase, and (d) pure rutile.

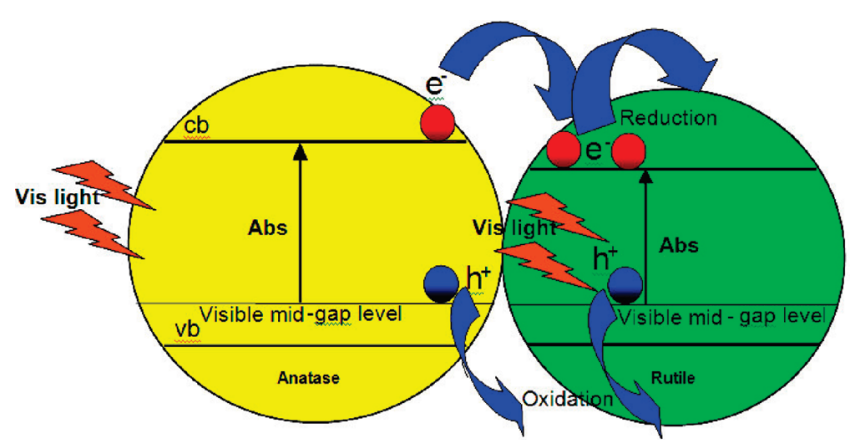

Figure 16. Electron transfer mechanism in N-doped anatase rutile heterojunction.

activity observed for the heterojunctions can be therefore, 673 correlated to the combined band gap narrowing effect of 674 the nitrogen and electron hole separating effect of rutile. $\quad 675$

3.3.2. Luminescence Studies. Information regarding 676 the presence of surface states, formation of photo induced 677 charge carriers, and their recombination kinetics can be 678 drawn from the photoluminescence (PL) spectrum of a 679 
(54) Liqiang, J.; Yichun, Q.; Baiqi, W.; Shudan, L.; Baojiang, J.; Libin, Y.; Wei, F.; Honggang, F.; Jiazhong, S. Sol. Energy Mater. Sol. Cells 2006, 90, 1773-1787.

(55) Georgekutty, R.; Seery, M. K.; Pillai, S. C. J. Phys. Chem. C 2008, 112, 13563-13570.

(56) Gandhe, A. R.; Fernandes, J. B. J. Solid State Chem. 2005, 178, 2953-2957.

(57) Shang, J.; Yao, W. Q.; Zhu, Y. F.; Wu, N. Appl. Catal., A 2004, 25, 257 . band-band and the excitonic PL intensities, which results in an increase in photocatalytic activity. Thus, the lowest PL intensity and the very high visible light activity of nitrogen doped anatase rutile heterojunctions can be explained on the basis of efficient charge separation at the anatase-rutile interface. It is known that the conduction band edge of rutile is approximately $0.2 \mathrm{eV}$ lower than that of anatase. ${ }^{7,18} \mathrm{On}$ this basis, the model that the photoexcited electrons (from the visible midgap level) are effectively transferred from the conduction band of anatase to that of rutile has been proposed.

\section{Conclusions}

Nitrogen doped anatase-rutile heterojunctions having high visible light photocatalytic activity were developed through an ionic intermediate [ $\mathrm{Ti}\left(\mathrm{H}_{2} \mathrm{O}\right)$ (edta)]. Low temperature crystallizations of heterojunctions were characterized using DSC, TGA, XRD, HRTEM, and Raman techniques. The nature of dopants was investigated using FT-IR spectroscopy, XRD, and XPS techniques. Conclusive evidence for the formations of both $\mathrm{O}-\mathrm{Ti}-\mathrm{N}$ and $\mathrm{N}-\mathrm{Ti}-\mathrm{N}$ bonds were observed from FTIR and XPS studies, and substitutional nitrogen doping was found to have an enhancing effect on the photocatalytic activities of heterojunctions. The most active $\mathrm{N}$-doped heterojunction obtained at $400{ }^{\circ} \mathrm{C}$ showed a 9 -fold enhancement for the visible light decomposition of methylene blue in comparison to the commercial catalyst Degussa P-25. The heterojunction has lower luminescence intensity as a result of better electron hole separation, and better textural properties in comparison to Degussa P-25. The highest photocatalytic activity of the optimum sample (1.5 ED-TiO 2400 ) was due to the combined effect of better electron hole separation, a lower band gap resulting from effective nitrogen doping, and nanocrystalline nature compared to the standard photocatalyst.

Acknowledgment. The authors would like to thank Enterprise Ireland for funding (CFTD/06/IT/326) and Dr. John Colreavy (Director, Centre for Research in Engineering Surface Technology) and Dr. Niall Stobbie for reviewing the paper. The authors would like to dedicate this paper to Professor John M. Kelly, on the occasion of completing his 37 years of teaching and research (celebration of chemistry) at Trinity College Dublin, Ireland.

Supporting Information Available: Further details are given in the supporting tables $1-3$ and figures $1-13$. This material is available free of charge via the Internet at http://pubs.acs.org.

(58) Jing, L. Q.; Fu, H. G.; Wang, D. J.; Wei, X.; Sun, J. Z. Acta Phys. Chim. Sin. 2005, 21, 38.

(59) Li, X. Z.; Li, F. B.; Yang, C. L.; Ge, W. K. J. Photochem. Photobiol., A 2001, 141, 209.

(60) Xin, B. F.; Jing, L. Q.; Ren, Z. Y.; Wang, B. Q.; Fu, H. G. J. Phys. Chem. B 2005, 109, 2805.

(61) Li, F. B.; Li, X. Z. Appl. Catal., A 2002, 228, 15

(62) Yu, J. G.; Yu, H. G.; Chen, B.; Zhao, X. J.; Yu, J. C.; Ho, W. K. J. Phys. Chem. B 2003, 107, 13871. 